\title{
ESCREVENDO EM TERRA DE HOMEM NENHUM: QUESTÕES DE GÊNERO E TRADUÇÃO'
}

\author{
Susan Bassnett ${ }^{1}$ \\ 1-University of Glasgow, Glasgow, Escócia \\ Tradução de Naylane Matos² \\ ²Universidade Federal de Santa Catarina, Florianópolis, Santa Catarina, Brasil
}

\begin{abstract}
Resumo: Este artigo centra-se em questões de gênero e tradução levantas por teóricas/os feministas e dos Estudos da Tradução, na década de 1970. Susan Bassnett discute os argumentos apresentados pela crítica feminista - no que tange o modo como a sociedade marginaliza as mulheres e seus processos criativos - e por teóricas/os de tradução - em relação ao processo manipulativo envolvido na suposta "inocente" transferência de textos de uma cultura para outra - e como essas áreas têm sido conectadas. Seguindo a perspectiva de Bassnett, esta tradução almeja ser uma atividade política na qual são eleitas estratégias feministas de tradução a fim de tornar o próprio conteúdo do texto visível na tradução.

Palavras-chave: Tradução e Gênero; Tradução Feminista; Políticas de Tradução.
\end{abstract}

\footnotetext{
${ }^{1}$ Writing in no man's land: questions of Gender and Translation. Texto inicialmente publicado em Ilha do Desterro: A Journal of English Language, Literature in English and Cultural Studies. Florianópolis, n. 28, 1992. pp. 63-74. Sua tradução foi autorizada pela autora Susan Bassnett, a quem gentilmente agradecemos, e pelo periódico. (N. da T.)
} 


\title{
WRITING IN NO MAN'S LAND: QUESTIONS OF GENDER AND TRANSLATION
}

\begin{abstract}
This paper centers on questions of gender and translation raised by feminist scholars and Translation Studies scholars in the 1970s. Susan Bassnett discusses the arguments shed light by the feminist criticism - concerning ways in which societies marginalize women and women's creative processes - and those argued by translation scholarship - concerning the manipulative processes involved in the supposedly "innocuous" transfer of texts from a culture to another - and how these areas have been connected. Following the Bassnett's point of view, this translation intends to be a political activity in which feminist strategies of translation are chosen in order to make the own content of the text visible in the translation.
\end{abstract}

Keywords: Translation and Gender; Feminist Translation; Politics of Translation.

Uma das principais inovações da crítica literária nos últimos vinte anos tem sido o debate proporcionado pelas escritoras feministas sobre os problemas de gênero e linguagem. Enquanto estudiosas feministas anglo-americanas têm focado mais nos debates sociológicos relativos às mulheres, na construção de gênero em diferentes contextos culturais e na historiografia, em outros lugares a atenção desloca-se para a investigação das tão inflamadas questões de gênero e linguagem, a relação entre escrita, leitura e o corpo.

Viemos de uma longa trajetória de pensamento simplista que prevaleceu quando eu era uma estudante na década de 1960, na qual as tentativas de discutir a linguagem e o feminino foram recebidas com questões desdenhosas por críticos (homens) sobre como alguém poderia determinar o sexo de quem escreve a partir da simples leitura de um trecho do texto. Naquela época, quando a teoria feminista ainda estava em seus primórdios, era difícil contestar aquele tipo de argumento, que também vinha acompanhado da linha de raciocínio: "nunca houve nenhuma mulher gênia". Mas na década de 1970 toda a questão de gênero e linguagem tornouse assunto de reflexões bastante sofisticadas e, pela primeira vez, 
a atenção deslocou-se da discussão sobre o sexo de quem escreve para questões envolvendo as marcas de gênero codificadas no texto. Assim, Hélène Cixous, em seu tão influente ensaio "Le Rire de la Meduse" (1975), pôde propor mudança da noção do "feminino" como parte de uma lógica binária que se opõe à noção do "masculino", enquanto a primeira é atribuída às mulheres e a segunda aos homens, e, no lugar, conduzir à noção do Feminino como transcendente de distinções biológicas.

Jean Genet, um homem, é, portanto, uma das figuras que Cixous propõe como um escritor "feminino", porque, em sua interpretação do termo, o feminino envolve o entrelugar de dois polos entre masculino e feminino:

Admitir que escrever é justamente trabalhar (no) entre, interrogar o processo do mesmo e do outro sem o qual nada vive, desfazer o trabalho de morte, é primeiramente querer os dois, e os dois juntos, o conjunto de um e outro não congelado nas sequências de luta e de expulsão ou outra via para a morte, mas dinamizados ao infinito por uma incessante troca de um e outro sujeito diferente. [Tradução de Luciana Eleonora de Freitas Calado Deplagne, 2017]

É significativo que Cixous esteja desenvolvendo sua noção de entrelugar exatamente no mesmo período em que se formava a recém disciplina Estudos da Tradução, e de fato os Estudos da Tradução desenvolvem-se paralelamente ao desenvolvimento da teoria feminista na década de 1970, embora as duas áreas tenham permanecido à parte até muito recentemente. Em termos gerais, no entanto, o significado de muito do trabalho de teóricas, como Julia Kristeva, Luce Irigaray, Hélène Cixous, Elisabetta Rasy e muitas outras, foi sua recusa em continuar olhando o mundo em termos de oposições binárias homem-mulher, masculino-feminino, pai-mãe, apesar das visões bastante diferentes, muitas vezes conflituosas, que elas proclamavam. Semelhantemente, uma das principais preo- 
cupações da maioria dos/as estudiosos/as que atuavam no campo dos Estudos da Tradução nos anos de 1970 era ir além do conceito binário de equivalência e encorajar a noção de equivalência baseada na diferença cultural, ao invés de algumas semelhanças presumidas entre sistemas linguísticos. Gideon Toury, por exemplo, discute a questão das normas que ditam a composição de um texto na literatura fonte e das que ditam a formulação de uma tradução e declara que:

sob nenhuma circunstância os dois conjuntos de normas... podem ser totalmente idênticos: pois as normas de tradução têm a ver não apenas com a formação e formulação do texto traduzido (isto é, a fase de (re)composição do processo de tradução), mas também com a inevitável decomposição do texto fonte; a atribuição de relevância a algumas de suas características, em um determinado nível (ou níveis); e com a fase crucial da transferência dessas características além das fronteiras semióticas, portanto, com as relações de tradução, aquelas relações observáveis realmente obtidas entre os textos traduzido e fonte ao final do processo. ${ }^{2}$

Os excertos aqui citados são escritos em linguagem figurada, envolvendo imagens de morte e decomposição. No entanto, ambos se preocupam em ir além da morte e nisso também há forte paralelo entre o trabalho da teoria feminista psicanalítica e dos Estudos da Tradução. Como aponta Walter Benjamin:

Tão longe a tradução está de ser a equação estéril entre duas línguas mortas que, precisamente a ela, dentre todas as formas, mais propriamente compete atentar para aquela maturação póstuma da palavra estrangeira, e para as dores do parto de sua própria palavra. [Tradução de Susana Kampff Lages, 2010]

${ }^{2}$ Tradução nossa. (N. da T.) 
A suposição aqui é de que a tradução é de alguma forma equiparada ao princípio maternal, que cuida e gera. Tradução, nos termos de Benjamin, é o processo que dá vida ao texto da língua fonte, evidenciando-o em uma nova língua; não é uma atividade envolvendo conflito entre dois sistemas literários que tem de resultar na derrota de um e na vitória de outro. A terminologia de perda e ganho, a ideia de que a tradução é de alguma forma uma atividade secundária, inferior ao ato da escrita, que a tradução está hierarquicamente mais baixa que o "privilegiado" original é rejeitada em favor da noção que enxerga a tradução e a escrita como interconectadas, onde uma assegura a sobrevivência da outra. Da mesma forma, a rejeição de Cixous da oposição binária entre masculino e feminino conduz a uma reformulação da velha hierarquia que coloca a mulher abaixo do homem. Homem, o Original, superior à Mulher, a Tradução, criada (pelo menos de acordo com as versões Bíblicas da Criação) da costela do homem.

Ao discutir a metáfora de Jacqueline Risset, da tradutora como parteira e mãe, Nicole Ward Jouve, bilíngue e bicultural, comenta que:

A/o tradutor/a é um ser intermediário. Como palavras em tradução, ela/ele deriva infinitamente entre significados. Ela/ele tenta ser a/o mediador/a que sugere astutamente outras leituras na língua estrangeira para além daquelas disponíveis na tradução. Há uma palavra em inglês que, como langue, designe tanto o órgão corporal quanto a existência das palavras, a estrutura da língua? Poderia ser language, poderia ser tongue? Você é levada/o a refletir sobre como uma tradução particular é construída. O que se perde, o que se ganha, como e o que se altera na passagem de uma língua para outra. ${ }^{3}$

${ }^{3}$ Tradução nossa. (N. da T.) 
Um bom tempo e energia foram gastos analisando o papel do/a tradutor/a, na tentativa de descrever esse papel de modo que nem privilegiasse o/a tradutor/a em relação ao autor/a nem o/a colocasse em posição de subserviência, e é significativo que muito do trabalho recente, refiro-me ao trabalho de meados de 1980 em diante, tenha sido iniciado pelas mulheres.

O velho conceito binário de tradução via o texto "original" e o traduzido como dois polos. Teóricas/os dos Estudos da Tradução então empenharam-se em desconstruir a hierarquia implícita em tal terminologia, adotando o uso de texto fonte e texto alvo, mas ainda assim tendia para a implicação metafórica da polarização ("fonte" com conotação feminina através de uma gama de seus significados e "alvo" com implícita conotação militarista, logo masculina). Em oposição, teóricas/os da tradução feminista optaram por trabalhar com a ideia do entrelugar de quem traduz, do lugar entre os polos e, se esses polos são metamorfoseados em masculino e feminino, então o espaço não é nem um nem outro, torna-se andrógino e até bissexual. Não é por acaso que significativos e potentes trabalhos que investigam tradução e gênero centram-se em torno de escritoras lésbicas ou bissexuais, em particular, o grupo de Nicole Brossard em Quebec $^{4}$. Significativamente, esse grupo rejeita tanto a velha crítica orientada para o/a escritor/a [writer-oriented] quanto a mais nova orientada para o/a leitor/a [reader-oriented], argumentando que nenhum dos elementos deveria ser priorizado. Kathy Mezei descreve o processo de tradução como "um ato da combinação de leitura e escrita”, uma vez que a/o tradutor/a é tanto leitor/a como escritor/a: "Quando eu traduzo, eu leio o texto... então, leio e releio o texto, e então, o escrevo em minha língua, em minhas palavras: eu escrevo minha leitura e a leitura reescreve minha escrita" 5 .

Essa noção de tradução é bastante diferente daquela apresentada por George Steiner, cuja perspectiva de tradução envolve a "pene-

${ }^{4}$ Ver o periódico Tessera e os trabalhos de Nicole Brossard, Annie Brisset, Barbara Godard, Suzanne Lamy, Daphne Marlatt etc.

${ }^{5}$ Tradução nossa. (N. da T.) 
tração apropriada" do texto fonte, então, o texto é capturado e o tradutor compensa o ato de agressão com um gesto de restituição. Lori Chamberlain, em um dos artigos mais importantes que datam o surgimento das discussões de tradução e gênero, examina o modelo de Steiner e aponta que ele "parece insistir que esse paradigma é universal e que os papéis masculino e feminino que descreve são mais "essenciais" do que "acidentais" " [Tradução de Norma Viscardi, 1998]. Lori Chamberlain contesta as suposições sobre relações de gênero/sexo implícitas na obra de Steiner, assinalando que esta segue um influente viés patriarcal que tende a ser considerado intrínseco ao pensamento da literatura ocidental.

Uma das metáforas chave do pensamento tradicional sobre tradução é das "belas infieis". Essa imagem, em sua interpretação tradicional, sugere que a tradução pode ser comparada à mulher, se é bela é infiel, enquanto uma tradução feia ou inadequada seria fiel à sua fonte. Não é necessário comentar a natureza sexista dessa proposição, já que ela própria é conspícua, mas tornou-se tão influente no pensamento contemporâneo que ainda é regularmente usada tanto por homens quanto por mulheres, embora seja absurda. A questão, é claro, é que é uma metáfora construída em uma época em que a fidelidade na tradução era profundamente significante (basta pensarmos nas descrições das traduções nos séculos XVII e XVIII como "espelhos", "cópias", definidas em relação ao mais perfeito original, precisando ser justificadas em termos de proximidade em relação a este original). Os trabalhos em Estudos da Tradução, em paralelo com o pensamento pós-modernista, têm abandonado a ideia de fidelidade como um ideal, rejeitando-a como espúria da mesma maneira que a noção de equivalência como semelhança foi rejeitada, mas a imagem da "bela infiel" ainda persiste.

Em 1986, fui convidada para dar uma palestra para a União Tcheca de Tradutores/as, em Praga, e elaborei um título que acreditava ser autêntico. Como eu estava lidando com questões de leitura e estratégias de tradução e contestando a ideia da abordagem normativa de tradução, optei por intitular minha fala "Sendo Infiel”. O título causou bastante hostilidade e a sessão de discussão 
foi bem acalorada. Nas semanas seguintes, eu comecei a buscar uma gama de outras mulheres que usavam a mesma imagem, começando por "Taking Fidelity Philosophically" de Barbara Johnson - na qual ela sugere que a/o tradutor/a deveria ser considerada/o "não como cônjuge obediente, mas como bígama/o fiel" - até artigos de Barbara Godard, Sherry Simon, Suzanne de Lotbinière -Harwood, dentre outras que questionavam o modelo tradicional da tradução "feminina" subordinada ao superior original "masculino". Definitivamente, havia uma sensação de que as mulheres estavam propondo teorias de tradução alternativas e em 1985 havia sido publicado a extensa obra de Myriam Diaz-Diocaretz sobre feminismo e tradução Translating Poetic Discourse: Questions of Feminist Strategies in Adrienne Rich.

Diaz-Diocaretz lida com uma questão pontual: o papel da/o tradutor/a na tradução de um texto especificamente feminista, e argumenta que é preciso mais do que um pensamento sistemático sobre linguagem e gênero. Ela não chega a fazer sentenças prescritivas sobre a necessidade de a/o tradutor/a compartilhar o viés de gênero e a ideologia da/o autor/a original, mas adverte contra a "traição da mensagem", argumentando que:

Autoras escrevendo de uma perspectiva conscientemente identificada pela/como/de mulher [woman-identified], na qual textos são criados a fim de ampliar as possibilidades semânticas da mulher enunciadora, demandam cooperação adicional por parte de quem traduz. ${ }^{6}$

Cooperação não apenas de quem traduz; em 1986, Lucie Armitt, minha então aluna de pós-graduação na Warwick, escreveu um trabalho de mestrado no qual examinou estratégias editoriais para a tradução de escrita de mulheres. Ela realizou um levantamento de editoras britânicas, incluindo as editoras principais, as de

${ }^{6}$ Tradução nossa. (N. da T.) 
média escala e as especializadas em traduções, e seus resultados foram notáveis. Apesar do boom na escrita de mulheres, em geral, e o fato dessas editoras competirem entre si para ampliar suas listas de estudos de mulheres, apenas uma editora alegou refletir sobre questões de tradução. As editoras feministas Virago e Women's Press responderam desdenhosamente, então, Lucie Armitt concluiu que embora gênero e linguagem seja uma agenda supostamente importante para todas as editoras, ela desaparece quando envolve a tradução. Ela sugere que isso pode estar relacionado com o baixo status da tradução e também com a tradição monolíngue de muitas editoras britânicas ${ }^{7}$.

Em um artigo intitulado "Theorizing Feminist Discourse/Translation”, Barbara Godard propõe uma noção radical de tradução que prioriza a questão de gênero:

\begin{abstract}
Apesar do tradicional topos negativo da tradução, a 'diferença' torna-se positiva na tradução feminista. Bem como a parodia, a tradução feminista ressignifica a diferença apesar da semelhança. Como a teoria feminista tem se preocupado em demonstrar, a diferença é um fator chave no processo cognitivo e na práxis crítica... A tradutora feminista, afirmando sua diferença crítica e seu prazer no interminável processo de releitura e reescrita, exibe os sinais de sua manipulação do texto. Mulheres tecendo texto em tradução implicará na substituição da tradutora modesta e recatada. ${ }^{8}$
\end{abstract}

A tradutora de Barbara Godard rejeita a história de traduzir como uma atividade secundária, liberta-se de toda modéstia, falsa ou não, e exibe sua posse/re-posse do texto. Ela chega ao ponto de sugerir que a tradutora a(1)tiva "exibe sua assinatura em itálico em nota de rodapé - e até em prefácio”. Sua tradutora não

\footnotetext{
${ }^{7}$ Lucie Armitt, trabalho de mestrado, Pós-Graduação em Teoria da Literatura Comparada e Estudos da Tradução, Universidade de Warwick.

${ }^{8}$ Tradução nossa. (N. da T.)
} 
é recatada, muito menos invisível, é uma presença física real no texto que ela traduz.

A esta altura, leitoras/es brasileiras/os podem começar a ouvir ecos de algo familiar, e com razão. A escola canadense, especialmente, tem feito conexões entre a teoria feminista e a teoria pós-colonial, assim, a tradutora a(l)tiva, em sua nova forma de relacionarse com o texto, apresenta muitos paralelos com as teorias propostas pelos irmãos Campos, como por exemplo as metáforas de canibalismo e vampirismo 9 como uma forma de tentar liberar o discurso da tradução enquanto busca-se elevar o status da/o tradutor/a:

Com uma tal falta de gente coexistível, como há hoje, que pode um homem de sensibilidade fazer senão inventar os seus amigos, ou quando menos, os seus companheiros de espírito? (Fernando Pessoa)

A minha maneira de amá-los é traduzi-los. Ou degluti-los, segundo a Lei Antropofágica de Oswald de Andrade: só me interessa o que não é meu. Tradução para mim é persona. Quase heterônimo. Entrar dentro da pele do fingidor para refingir tudo de novo, dor por dor, som por som, cor por cor.

Aqui, Augusto de Campos corporifica o processo de tradução de maneira muito similar à corporificação do feminino proposta por Suzanne de Lotbinière-Harwood, ao discutir sua tradução de Lise Gauvin:

Eu não sou ela. Ela escreveu no masculino genérico. Minha prática de tradução é uma atividade política que visa fazer a língua falar pelas mulheres. Então, minha assinatura

\footnotetext{
${ }^{9}$ Ver Campos, Augusto. Verso, Reverso e Controverso. São Paulo: Perspectiva, 1978; Campos, Haroldo. Deus e o Diabo no Fausto de Goethe. São Paulo: Perspectiva, 1981.
} 
em uma tradução significa: esta tradução usou cada possibilidade de estratégia de tradução feminista para tornar o feminino visível na língua... a tradução é um ato de invenção linguística que geralmente enriquece o texto original ao invés de traí-lo. ${ }^{10}$

No começo deste artigo, eu destaquei que os Estudos da Tradução desenvolveram-se cronologicamente em paralelo às teorias feministas da linguagem e também, poderíamos acrescentar, ao desenvolvimento da teoria pós-moderna. É interessante que grande parte desse trabalho não tenha sido conectado e, na minha opinião, estamos em um momento no qual os encontros entre os grupos separados estão finalmente começando a acontecer. Há muito tempo se argumenta, por exemplo, que o nível do discurso de muitos/ as teóricos/as da tradução permaneceu desatualizado e, no recente ano de 1985, Raymond Van den Broeck ainda achava necessário atacar a escola de tradução do "julgamento de valor", cujo tempo era gasto classificando traduções em uma (altamente subjetiva) ordem de mérito, enquanto em um ensaio publicado em 1991, André Lefevere fala sobre a necessidade de ver a tradução em termos de "empacotamento" e argumenta que hoje estamos em uma posição de examinar os processos de manipulação, literários e políticos, que controlam nossas vidas.

Os Estudos Feministas lançam luz sobre as formas pelas quais as sociedades marginalizam mulheres e seus produtos criativos e os Estudos da Tradução têm cada vez mais desvendado os processos manipulativos que envolvem a suposta inocente transferência de textos de uma cultura para outra. Então, uma mirada para a linguagem figurada que descreve a tradução pode ser significativa de várias maneiras. Dessa forma, a metáfora de fidelidade ao original, geralmente apoiada em termos de gênero, nos diz muito sobre as estruturas sociais hierárquicas que cunham e utilizam essa imagem. O Original, o Pai, exalta-se em uma posição superior à cópia, o

${ }^{10}$ Tradução nossa. (N. da T.) 
feminino, seja esposa, amante ou mãe. E a metáfora da penetração, da posse sexual do texto deriva também do mesmo sistema de valores patriarcais, um sistema de proprietários e propriedades, colonizadores e colonizados, estupradores e vítimas. O mais significativo, talvez, seja o modo no qual cada metáfora reforça o persistente problema com que a tradução tem que lidar: o baixo status imposto à tradução e aos textos traduzidos.

A introdução das questões de gênero à tradução nos convida a considerar as implicações reais do encontro de quem traduz com o texto fonte e qual tipo de combinação entre os textos fonte e alvo resulta desse encontro. Se nós aceitamos que a/o tradutor/a não é, e nunca poderia ser, um filtro transparente pelo qual um texto passa, mas sim uma fonte muito potente de energia criativa transicional (e esta é a premissa fundamental das/os teóricas/os dos Estudos da Tradução), pensar em termos de gênero, portanto, eleva a consciência das complexidades textuais nos papéis de quem escreve e de quem lê. Neste sentido, por exemplo, Myriam Diaz-Diocaretz lida com o espinhoso problema de traduzir "Twenty-One Love Poems" de Adrienne Rich ao espanhol, observando que "Veinte poemas de amor y una canción desesperada", de Pablo Neruda, despertará atenção imediata das/os leitoras/es dela. O problema aqui não são duas sequências de poemas com títulos similares; é o fato de que a poesia de Neruda é uma poesia heterossexual, escrita de um homem para uma mulher, enquanto que a poesia de Rich é enfaticamente homossexual, escrita de uma mulher para outra mulher, e, em termos linguísticos, o tradutor enfrenta a dificuldade adicional de traduzir para uma língua marcada gramaticalmente pelo gênero. Diaz-Diocaretz também nota as restrições impostas pelas diferentes convenções sociais:

Usar o masculino para o adjetivo 'juntos' (together) seria uma forma comum e gramaticalmente legítima de indicar a dualidade... mas... abandonar esta forma seria um deslocamento de referência... Como um/a tradutor/a ciente da tradição moral e social e das convenções na cultura hispâ- 
nica como um todo, no contexto do meu próprio horizonte de possíveis leitoras/es, usar o adjetivo no feminino plural (juntas) seria mais que audacioso. ${ }^{11}$

Aqui, as questões de gênero no texto devem ser tratadas em relação às convenções sociais e as expectativas do mundo fora do texto. A tarefa da/o tradutor/a é ainda mais complicada pelas opiniões taxativas de Rich sobre como sua poesia deve ser lida, argumentando que remover os sinais de amor lésbico inscritos no texto é um ato de imperialismo patriarcal. Diaz-Diocaretz descreve ela mesma como uma tradutora "dividida entre a mensagem da poeta... e as restrições que limitam as normas e convenções da voz poética de uma mulher na tradição literária hispânica”.

Em contrapartida, minha própria tradução do romance autobiográfico de Gabriele D'Annunzio, Il fuoco, apresentou outras dificuldades. Fascinada pelo texto, que apresenta a leitura do amaldiçoado caso de amor entre D'Annunzio e a grande atriz Eleonora Duse, eu aceitei um convite para traduzi-lo como um romance representativo da virada do século Decadentista. Eu havia escrito extensivamente sobre Duse e conhecia o contexto da escrita do romance de D’Annunzio, mas provou-se ser extremamente difícil encontrar o equilíbrio entre a dominação masculina do homem que se justifica por meio da ficção pelo tratamento terrivelmente cruel de sua amante e minha própria militância. Comecei a pensar se não seria impossível esperar que uma tradutora com uma gama de perspectivas sobre o patriarcado e um escritor com pontos de vista diametralmente opostos pudessem se unir. Enquanto Diaz-Diocaretz descreve-se como "dividida", eu descrevi-me como envolvida em um conflito com o escritor, "afrontando" ou "lutando" com o texto e sua ideologia, exigindo o direito de trabalhar criativamente como uma tradutora e preocupada que minha "infidelidade" não fosse simplesmente política. Transformar um romance que é um hino à criatividade masculina em um panfleto feminista teria sido absur-

${ }^{11}$ Tradução nossa. (N. da T.) 
do, pois a força do livro consiste no estilo lírico de D'Annunzio, que é sempre hiperbólico. No final, a tradução em inglês reflete nossa luta e, no processo de luta com o texto e seu autor, cheguei a uma leitura muito mais complexa da que havia feito a princípio, uma leitura que vê o livro inteiro como uma luta não apenas entre dois personagens, mas também entre princípios masculino e feminino, entre fogo e água, primavera e outono, vida e morte. ${ }^{12}$

A tradução é uma atividade complexa e multifacetada que exige tempo e cuidado, comprometimento e estudo, e os Estudos da Tradução têm buscado analisar sistematicamente algumas das questões envolvidas. O trabalho iniciado que considera a tradução em relação às questões de gênero é tão importante para os homens quanto para as mulheres, pois busca explorar em maior profundidade as dimensões linguísticas, culturais e filosóficas do processo de tradução. Em uma palestra recente sobre esse assunto, fui solicitada pela plateia a propor uma metáfora para o futuro que poderia nos levar além dos modelos anteriores, com suas ressonâncias de sexismo e colonialismo, além das metáforas de inadequação e traição, de estupro e penetração, de fidelidade e infidelidade. Minha proposta, por mais idealista que pareça, é por uma teoria orgásmica de tradução, na qual os elementos são fundidos em um novo encontro holístico que é mútuo, prazeroso e respeitoso. Lori Chamberlain diz que qualquer teoria feminista da tradução "será finalmente utópica”. Eu sinceramente espero que ela esteja errada.

12 Ver D’Annunzio, Gabriele. Il Fuoco. Tradução de Susan Bassnett. London: Quartet, 1991. 


\section{Referências}

Armitt, Lucie. Unpublished MA paper, Graduate School of Comparative Literary Theory and Translation Studies, University of Warwick.

Benjamin, Walter. "A tarefa do tradutor". Tradução de Susana Kampff Lages. In: Heidermann, Werner (Org.). Clássicos da teoria da tradução. Florianópolis: UFSC/Núcleo de Pesquisa em Literatura e Tradução, v. 1, 2010. p. 202-231.

Broeck, Raymond Van den. "Second thoughts on translation criticism". A model of its analytic function In: Hermans, Theo (ed.). The Manipulation of Literature. London: Croom Helm, 1985. p. 54-63.

Campos, Augusto. Verso, reverso e controverso. São Paulo: Perspectiva, 1978(a).

Campos, Haroldo. Deus e o Diabo no Fausto de Goethe. São Paulo: Perspectiva, 1981(b).

Chamberlain, Lori. "Gênero e a metafórica da tradução. Tradução de Norma Viscardi”. In: Ottoni, Paulo (Org.). Tradução: a prática da diferença. Campinas, SP: Fapesp/Unicamp, 1998.

Cixous, Hélène. "O riso da Medusa". Tradução de Luciana Eleonora de Freitas Calado Deplagne. In: Brandão, Izabel et al. (Orgs.). Traduções da cultura: perspectivas críticas feministas (1970-2010). Florianópolis: EDUFAL; Editora da UFSC, 2017. p. 129-155.

Diaz-Diocaretz, Myriam. Translating Poetic Discourse: Questions of feminist strategies in Adrienne Rich. Amsterdam: John Benjamin, 1985.

Godard, Barbara. “Theorizing Feminist Discourse/Translation”. In: Bassnett, Susan; Lefevere, André (eds.). Translation, History and Culture. London: Pinter, 1990, p. 89-96. 
Johnson, Barbara. "Taking Fidelity Philosophically". In: Graham, Joseph (ed.). Difference in Translation. Ithaca and London: Cornell University Press, 1985. p. 142-148.

Jouve, Nicole Ward. To fly/to steal: no more? Translating French feminisms into English, White Woman Speaks with Forked Tongue: Criticism as Autobiography. London: Routledge, 1991.

Lefevere, André. "Translation and Comparative Literature: The Search for the Center". TIR Languages and Cultures in Translation Theories, [s.l], v. IV, n. 1, 1st Semester, 1991, p. 129-145.

Lotbinière-Harwood, Suzanne de. About the her in other. Preface to Lise Gauvin, Letters from an Other. Toronto: Women's Press, 1989.

Mezei, Kathy. "The reader and the decline". Tessera: L 'Ecri lure comme Lecture: September, 1985. p. 21-31.

Steiner, George. After Babel. London and New York: Oxford University Press, 1975.

Toury, Gideon. "Translation, literary translation and pseudotranslation". Comparative Criticism, [s.1], v. 6, 1984. p. 73-85.

Recebido em: 05/08/2019

Aceito em: 31/10/2019

Publicado em janeiro de 2020

Susan Bassnett. E-mail: Susan.Bassnett@glasgow.ac.uk ORCID: https://orcid.org/0000-0002-9468-9800

Naylane Matos. E-mail: naylaneam@gmail.com ORCID: https://orcid.org/0000-0003-2077-1534 